\title{
TLR4-dependent activation of dendritic cells by an HMGB1-derived peptide adjuvant
}

\author{
Rebecca Saenz ${ }^{1}$, Diahnn Futalan', Lien Leutenez ${ }^{2}$, Fien Eekhout ${ }^{2}$, Jessie F Fecteau', Simeon Sundelius ${ }^{3}$, \\ Stig Sundqvist ${ }^{3}$, Marie Larsson ${ }^{3}$, Tomoko Hayashi ${ }^{1}$, Boris Minev ${ }^{1,4}$, Dennis Carson ${ }^{1}$, Sadik Esener ${ }^{1,5}$, \\ Bradley Messmer ${ }^{1 *}$ and Davorka Messmer ${ }^{1}$
}

\begin{abstract}
High mobility group box protein 1 (HMGB1) acts as an endogenous danger molecule that is released from necrotic cells and activated macrophages. We have previously shown that peptide Hp91, whose sequence corresponds to an area within the B-Box domain of HMGB1, activates dendritic cells (DCs) and acts as an adjuvant in vivo. Here we investigated the underlying mechanisms of Hp91-mediated DC activation. Hp91-induced secretion of IL-6 was dependent on clathrin- and dynamin-driven endocytosis of Hp91 and mediated through a MyD88- and TLR4-dependent pathway involving P38 MAPK and NFKB. Endosomal TLR4 has been shown to activate the MyD88-independent interferon pathway. Hp91-induced activation of pIRF3 and IL-6 secretion was reduced in IFNaßR knockout DCs, suggesting an amplification loop via the IFNaßR. These findings elucidate the mechanisms by which Hp91 acts as immunostimulatory peptide and may serve as a guide for the future development of synthetic Th1-type peptide adjuvants for vaccines.
\end{abstract}

\section{Introduction}

The adaptive immune response is commonly initiated via pathogen-associated molecular patterns (PAMPs) that are recognized by Toll-like receptors (TLRs) [1]. Dendritic cells (DC) are central for the initiation of adaptive immune responses and are activated by exogenous PAMPs such as lipopolysaccharides (LPS), CpG, or poly(I:C) [2] as well as endogenous signals of tissue and cell damage, sometimes referred to as alarmins or danger signals [3,4]. Alarmins can take the form of inflammatory cytokines secreted by cells proximal to the site of injury [5] or internal components of damaged cells. Evidence for the latter includes reports that necrotic cell lysates, more specifically heat shock proteins (HSPs) and high mobility group box protein 1 (HMGB1) in the lysates, can induce DC maturation [6-8].

HMGB1 was originally described as a nuclear protein that facilitates DNA bending and stabilizes nucleosome formation [9]. HMGB1 contains three domains, including two homologous DNA binding motifs termed A-

\footnotetext{
* Correspondence: bmessmer@ucsd.edu

'Rebecca and John Moores Cancer Center, University of California San Diego (UCSD), 3855 Health Sciences Dr., La Jolla, CA 92093-0815, USA

Full list of author information is available at the end of the article
}

and B-boxes, each approximately 80 amino acids long, and a negatively charged $C$-terminus [10,11]. In addition to the nuclear functions, HMGB1 is secreted by both macrophages and monocytes after exposure to LPS, TNF- $\alpha$ or IL-1 $\beta$ [12] and, through a feedback loop, acts back on monocytes by stimulating the synthesis of additional pro-inflammatory cytokines [13]. More recently, HMGB1 was identified as an endogenous alarmin, or damage-associated molecular pattern (DAMP) $[3,14]$. HMGB1 is released from necrotic cells to trigger inflammation [15] and act as an endogenous adjuvant [16]. Several receptors are implicated in HMGB1 mediated activation of cells, including the receptor for advanced glycation end-products (RAGE) $[17,18]$, toll like receptor 2 (TLR2), TLR4 [19-23], TLR9 [24], Mac-1 [25], syndecan-1 $[26,27]$, receptor-type tyrosine phosphatase$\zeta / \beta[26,28]$, and CD24/Siglec-10 [29].

Structure-function studies have revealed that the proinflammatory domain in HMGB1 maps to the B-box domain, which recapitulates the cytokine activity of full-length HMGB1 [30,31]. We have previously shown that a B-box domain derived peptide, named Hp91 acted as a potent maturation stimulus for DCs and induced a cytokine profile typical of a Th1-type response 
[32]. We recently showed that Hp91 potentiates antigen-specific humoral and cellular immune responses in vivo [33]. This study explored the mechanism by which Hp91 activates antigen presenting cells by investigating cellular uptake, receptor dependence, and signaling pathways. We found that Hp91-induced secretion of IL-6 was mediated through a MyD88/TLR4dependent pathway involving p38MAPK and NFKB.

\section{Materials and methods}

\section{Animals}

Female C57BL/6 mice 8-12 weeks of age were used for experiments. C57BL/6 mice were purchased from Charles River Laboratories (Boston, MA, USA). TLR4-/- and IL1R-/- mice were purchased from The Jackson Laboratories (Bar Harbor, ME, USA). IFN $\alpha \beta R-/-$ mice were purchased from B\&K Universal (England, UK). MyD88-/- and TLR7-/- mice were a gift from S. Akira (Osaka University, Osaka, Japan) and backcrossed for 10 generations onto the C57BL/6 background. Mice were bred and maintained at the Moores UCSD Cancer Center animal facility and all animal studies were approved by the Institutional Animal Care and Use Committee of UCSD and were performed in accordance with the institutional guidelines.

\section{Reagents}

The peptides, including Hp91 (DPNAPKRPPSAFFLFCSE), Hp121 (SIGDVAKKLGEMWNNTAA), scrambled Hp91 (ASLAPPFPNCFDPKSREF), and OVA-I (SIINFEKL) were all synthesized at GMP facilities by GenScript Corp (Piscataway, NJ, USA) and CPC Scientific (San Jose, CA, USA). Peptides were synthesized with an N-terminal biotin, acetyl, or fluorescent tag $(\mathrm{Cp} 488)$ as indicated in the figure legends. Peptides were routinely synthesized with greater than $95 \%$ purity. Peptides, reagents, and labware were endotoxin-free as determined by the manufacturer or a limulus amoebocyte assay (LAL) (Cambrex Corporation, East Rutherford, NJ), tested according to manufacturer's instructions. Peptides were dissolved in RPMI or PBS for in vitro and in vivo experiments respectively. Phenylarsine oxide and chlorpromazine (clathrin-mediated endocytosis inhibitors), sodium azide (energy-dependent endocytosis inhibitor), nystatin (caveolin-mediated endocytosis inhibitor), latrunculin B (phagocytosis inhibitor), amiloride (micropinocytosis inhibitor), and dynasore (dynamin inhibitor) were purchased from Sigma-Aldrich as endocytosis inhibitors. The p38 MAPK-specific inhibitor, SB203580, and the NFKB inhibitor, $N$-tosyl-L-phenylalanine chloromethyl ketone (TPCK), were purchased from Sigma-Aldrich. The MEK1 inhibitor, PD98059, was purchased from Cell Signaling Technology (Danvers, MA). As many of these inhibitors required solubilization in DMSO, DMSO was used as a negative control.

\section{Cell lines}

The J774 cell line was a gift from Maurizio Zanetti (UCSD) and was cultured in RPMI 1640 medium (Invitrogen), supplemented with $10 \mathrm{mM}$ HEPES (Invitrogen), penicillin (100 U/ml), streptomycin $(100 \mu \mathrm{g} / \mathrm{ml}), \mathrm{L}$-glutamine $(2 \mathrm{mM})$ (Invitrogen), and 10\% (vol/vol) fetal calf serum (Omega Scientific, Tarzana, CA). The RAW 264.7 cell line was a gift from Dong-Er Zang (UCSD) and was cultured as above, except with $5 \%$ (vol/vol) fetal calf serum (Omega).

\section{Generation of human monocyte-derived DCs}

Peripheral blood mononuclear cells were isolated from the blood of normal volunteers over a Ficoll-Hypaque (Amersham Biosciences, Uppsala, Sweden) density gradient. Anonymous blood samples were purchased from the San Diego Blood Bank; therefore, no institutional review board approvals were necessary. To generate DCs, peripheral blood mononuclear cells were allowed to adhere to culture plates for $1 \mathrm{~h}$. The non-adherent cells were washed off, and the adherent cells were cultured in RPMI 1640 medium (Invitrogen) supplemented with $50 \mathrm{mmol}$ 2-mercaptoethanol (Sigma-Aldrich), $10 \mathrm{mM}$ HEPES (Invitrogen), penicillin (100 U/ml), streptomycin $(100 \mu \mathrm{g} / \mathrm{ml})$, L-glutamine $(2 \mathrm{mM})$ (Invitrogen), and either $5 \%$ (vol/vol) human AB serum (Gemini Bio Products, West Sacramento, CA) or 1\% (vol/vol) human plasma (Valley Biomedical, Winchester, VA) and supplemented with GM-CSF (1000 U/ml) (Bayer HealthCare Pharmaceuticals, Wayne, New Jersey), and interleukin-4 (100 U/ml) (IL-4; R\&D Systems, Minneapolis, Minnesota) at days 0,2 , and 4. Immature human DCs (iDCs) were harvested on days 5-7.

\section{Generation of mouse bone marrow-derived DCs}

Bone marrow-derived DCs (BM-DCs) were prepared from C57BL/6 and knockout mice, as described by Inaba et al. [34] with minor modifications. Briefly, single bone marrow cell suspensions were obtained from femurs and tibias and depleted of lymphocytes, granulocytes, and Ia + cells by incubating with a mixture of monoclonal antibodies (mAbs; anti-CD4, anti-CD8, anti-B220/ CD45R, and anti-Ia) (antibody hybridomas were a gift from Ralph Steinman (Rockefeller)) and low-toxicity rabbit complement (Pel Freez Biologicals, Rogers, AR) for $60 \mathrm{~min}$ at $37^{\circ} \mathrm{C}$. Cells were re-suspended at a concentration of $10^{6}$ cells $/ \mathrm{ml}$ in RPMI 1640 medium (Invitrogen) supplemented with $50 \mathrm{mM}$ 2-mercaptoethanol (Sigma-Aldrich), $10 \mathrm{mM}$ HEPES (Invitrogen), penicillin (100 U/ml), streptomycin (100 $\mu \mathrm{g} / \mathrm{ml})$, L-glutamine (2 mM) (Invitrogen), 5\% (vol/vol) fetal calf serum (Omega), and $10 \mathrm{ng} / \mathrm{ml}$ recombinant murine granulocyte-macrophage colony-stimulating factor (GM-CSF) (J558L GM-CSF-secreting cells were a gift from Ralph Steinman). Fresh complete medium containing GM-CSF was added on days 2 and 4 of culture. Cells were collected for the experiments on days 5-7. 


\section{Confocal microscopy}

$1 \times 10^{5}$ immature human DCs were precooled on ice and subsequently incubated for $30 \mathrm{~min}$ on ice with biotinylatedHp91 or Hp121 to allow peptide binding. Cells were washed and then incubated for the indicated time at $37^{\circ} \mathrm{C}$. Cells were cytospun (Shandon Cytospin 2 centrifuge) onto glass slides, fixed, permeabilized with acetone, and stained with Streptavidin-Alexa 488 (Invitrogen) to visualize biotinylated peptides and Hoechst 33258 (Invitrogen) to visualize DNA. Cells were imaged on a Zeiss LSM confocal microscope.

\section{Binding/uptake studies}

For most experiments, iDCs or mouse BM-DCs were precooled on ice for $30 \mathrm{~min}$, as indicated in the figure legends. Cells were subsequently incubated for the indicated times and temperatures in culture medium with biotinylated peptides. Cells were washed, permeabilized with Cytofix/Cytoperm (BD Biosciences, Franklin Lakes, NJ), stained with Streptavidin-Alexa 488 (Invitrogen), and analyzed by flow cytometry. For experiments with endocytosis inhibitors, cells were pre-treated for 30 min with the indicated inhibitors or controls prior to incubation with the biotinylated peptides. For experiments with J774 mouse macrophages, cells were pre-cooled on ice, pre-treated with $30 \mathrm{~min}$ with the indicated inhibitors, and subsequently incubated for $30 \mathrm{~min}$ with fluorescently-labeled Hp91 (Cp488-Hp91). Cells were immediately analyzed by flow cytometry using the FACSCalibur (Beckon Dickinson, Franklin Lakes, NJ). Data were analyzed using the FlowJo software (Tree Star, Inc., Ashland, OR).

\section{Stimulation of DCs}

At days 5-7 of culture, DCs were either left untreated or were stimulated with indicated doses of peptide. For inhibition experiments, immature human DCs were pretreated with the indicated doses of SB203580, PD98059, $\mathrm{N}$-tosyl-L-phenylalanine chloromethyl ketone (TPCK), or DMSO control for 30 min prior to stimulation. For experiments with human DCs, supernatants were collected $48 \mathrm{~h}$ after stimulation and the level of IL- 6 analyzed by IL-6 ELISA (eBioscience, Inc. San Diego, CA). For experiments with mouse BM-DCs, supernatants were analyzed by ELISA (eBioscience), $24 \mathrm{~h}$ after stimulation.

\section{Immunizations and splenocyte preparation}

Mice were immunized s.c. with $50 \mu \mathrm{g}$ of OVA-derived SIINFEKL peptide (OVA-1). The SIINFEKL peptide was co-administered with PBS, Hp91 $(250 \mu \mathrm{g})$, or scrambled Hp91 $(250 \mu \mathrm{g})$. Peptides were re-suspended in PBS for all immunizations. Mice were boosted two weeks later and spleens and blood were collected one week after the final immunization. Single cell suspensions of splenocytes were prepared by mechanical disruption and separation through a $70 \mathrm{~mm}$ nylon cell strainer (BD Biosciences). Red blood cells were lysed using ammonium chloride buffer (Roche Diagnostics, Indianapolis, IN) and the splenocytes were subsequently re-suspended in RPMI 1640 medium (Invitrogen) supplemented with $10 \mathrm{mM}$ HEPES (Invitrogen), penicillin (100 U/ml), streptomycin $(100 \mu \mathrm{g} / \mathrm{ml})$, L-glutamine (2 mM) (Invitrogen), and 5\% (vol/vol) fetal calf serum (Omega).

\section{Enzyme-linked immunospot assay}

Freshly isolated splenocytes were plated in duplicate wells in an Immobilon-P (PVDF) bottom enzyme-linked immunospot (ELISpot) plate (Millipore, Millerica, MA, USA) precoated with $5 \mu \mathrm{g} / \mathrm{ml}$ monoclonal anti-mouse IFN- $\gamma$ antibody (Mabtech, Stockholm, Sweden). Splenocytes were cultured overnight at $37^{\circ} \mathrm{C}$ with $2.5 \mu \mathrm{g} / \mathrm{ml}$ SIINFEKL (OVA-I) peptide, $2.5 \mu \mathrm{g} / \mathrm{ml}$ ISQAVHAAHAEINEAGR (OVA-II) peptide, $5 \mu \mathrm{g} / \mathrm{ml}$ concanavalin A positive control (Sigma-Aldrich), or left unstimulated (medium only). After $18 \mathrm{~h}$, culture supernatants were collected for cytokine analysis and ELISpot plates were developed using $1 \mu \mathrm{g} / \mathrm{ml}$ biotinylated anti-mouse IFN- $\gamma$ antibody (Mabtech), Streptavidin-HRP, and TMB Substrate (Mabtech). The plate was scanned and the spots were counted using an automated ELISpot Reader System (CTL ImmunoSpot, Shaker Heights, OH, USA).

\section{Cytokine Release Assay}

Splenocytes were cultured overnight with $2.5 \mu \mathrm{g} / \mathrm{ml}$ OVA-I peptide, $5 \mu \mathrm{g} / \mathrm{ml}$ concanavalin A positive control (Sigma-Aldrich), or left unstimulated (media only). After $18 \mathrm{~h}$, cell culture supernatants were collected and analyzed for the presence of IL-2 by ELISA (eBioscience).

\section{Immunoblotting}

Mouse J774 or RAW 264.7 macrophages stimulated with Hp91 or LPS for 20, 40, or 60 minutes were lysed for $20 \mathrm{mi}-$ nutes on ice in RIPA lysis buffer $(10 \mathrm{mM}$ Tris $\mathrm{pH} 7.4$, $150 \mathrm{mM} \mathrm{NaCl}, 1 \%$ TritonX-100, $0.1 \%$ sodium deoxycholate, $0.1 \%$ sodium dodecylsulfate (SDS), $5 \mathrm{mM}$ EDTA supplemented with $1 \mathrm{mM}$ phenylmethylsulfonyl fluoride, Halt phosphatase inhibitor (Thermo Fisher Scientific, Rockford, IL), $1 \mathrm{mM}$ sodium vanadate, $1 \mathrm{mM}$ sodium fluoride, and complete protease inhibitor cocktail (Roche). Protein concentration was determined with the Detergent Compatible protein assay (Bio-Rad, Hercules, CA). The lysates were snap-frozen and stored at $-80^{\circ} \mathrm{C}$. Equal amounts of protein lysates were separated by gel electrophoresis with the use of a NuPAGE Novex 4\%-12\% Bis-Tris Midi Gel (Invitrogen) and transferred to polyvinylidene fluoride membranes (Bio-Rad). Membranes were washed with $1 \times$ TBST (TrisBuffered Saline Tween-20) and blocked for 1 hour at room temperature in 5\% milk/TBST. Membranes were probed overnight for phospho- p38, phospho (p)-interferon 
regulatory factor 3 (IRF3), p38, IRF3, glyceraldehyde-3phosphate dehydrogenase (GAPDH), or $\beta$-actin (Cell Signaling Technology). The next day, membranes were washed with $1 \times$ TBST and incubated with goat antirabbit or anti-mouse horseradish peroxidase-conjugated secondary antibodies (Santa Cruz Biotechnology, Santa Cruz, CA) diluted in 5\% milk/TBST for $1 \mathrm{~h}$ at room temperature. Antibodies were detected with the use of either an enhanced chemiluminescence detection kit (GE Healthcare, Piscataway, NJ) or SuperSignal West Femto Maximum Sensitivity Substrate (Thermo Fisher Scientific). In some experiments, cells were pre-treated with the endocytosis inhibitor Dynasore.

\section{Qualitative real-time PCR}

Qualitative real-time PCR (qPCR) was performed in a Stratagene Mx3005P (Agilent, Santa Clara, CA) for mouse IFN- $\alpha 2$ and GAPDH. GAPDH was used as an endogenous standard for normalization of the IFN- $\alpha 2$ gene. Briefly, $1.25 \times 10^{5} \mathrm{~J} 774$ macrophages/well were serum-starved overnight in a 96-well flat-bottom plate and stimulated in duplicate with LPS $(10 \mathrm{ng} / \mathrm{ml})$, acetylated $\mathrm{Hp} 91$ $(200 \mu \mathrm{g} / \mathrm{ml})$, or left unstimulated (media) for 6 hours. Cells were harvested and RNA was isolated using TRIzol as follows: the J774 cell pellets were lysed in approximately $1 \mathrm{ml}$ of TRIzol Reagent (Invitrogen) by repetitive pipetting. The cleared homogenate solution was incubated for $5 \mathrm{~min}$ at RT, $200 \mu \mathrm{l}$ of chloroform was added and samples were shaken for 15 seconds and incubated at RT for an additional 2-3 min. Samples were centrifuged at $12000 \times \mathrm{g}$ for 15 minutes at $4^{\circ} \mathrm{C}$. Pellets were washed with $1 \mathrm{ml} 75 \%$ RNAse-free ethanol, centrifuged for $7000 \times$ g for $5 \mathrm{~min}$ at $4^{\circ} \mathrm{C}$, and the RNA pellets were air dried. DNase was removed from samples using a Turbo DNAfree DNase treatment (Applied Biosystems/Ambion, Austin, TX). cDNA was synthesized using Superscript III-RT polymerase (Invitrogen) and related reagents as per the manufacture's instructions. qPCR samples were setup using Brilliant II SYBR Green QPCR Master Mix (Invitrogen) and the following Q-primers: IFN- $\alpha 2$ (For. 5 -ACTCTGTGCTT TCCTCGTGATGCT-3'; Rev. 5'ATCCAAAGTCCTGC CTGTCCTTCA-3') and GAPDH (For. 5'- TCACCACC ATGGAGAAGGC-3’; Rev. 5‘-GCTAACCAGTTGGTG GTGCA-3'). Primers were purchased from IDT. qPCR was performed on duplicate samples in a Stratagene Mx3005P. Amplification product lengths were confirmed on a DNA gel. Values are normalized against GAPDH controls.

\section{Statistical analysis}

Data were analyzed for statistical significance using unpaired or paired Student's $t$-test or the Log Rank test. Statistical analysis was performed using GraphPad software version 5.01 for Windows (GraphPad Software, San
Diego, CA, USA). A $p$ value $<0.05$ was considered statistically significant.

\section{Results}

\section{Hp91 amino acid sequence is critical for uptake and} activation of DCs

To gain insight into the mechanism of action of the DC stimulatory peptide Hp91, we investigated its physical interaction with DCs. Hp91 was taken up in a dose dependent manner (Figure 1A), which plateaued between 10 and 30 minutes (Figure 1B). The control peptide, Hp121, which also corresponds to a sequence present in HMGB1 and has the same length, a similar charge, and isoelectric point as Hp91 was not taken up by DCs and uptake of a scrambled version of $\mathrm{Hp} 91$, was significantly lowered (Figure 1C, 1D and 1E), suggesting that uptake of Hp91 is sequence specific and not due to overall charge. Confocal microscopy was used to distinguish between cellular binding and uptake and showed localization of Hp91 inside DCs. The control peptide Hp121 was not detected inside the cells, even after 30 minutes incubation at $37^{\circ} \mathrm{C}$ (Figure $1 \mathrm{C}$ ). Since the scrambled version of $\mathrm{Hp} 91$ interacted with DCs, although to a much lesser extent than Hp91 (Figure 1D and 1E), we examined if it had similar immunogenic properties as Hp91, which as we have previously described potentiates antigen-specific CD8+ T cell immune responses in vivo [33]. The scrambled version of $\mathrm{Hp} 91$ did not augment OVA-specific CD8+ CTL responses or IL-2 release (Figure $1 \mathrm{~F}$ and $1 \mathrm{G}$ ), suggesting that $\mathrm{Hp} 91$ functional activity is sequence specific.

\section{Hp91 enters dendritic cells via clathrin-mediated endocytosis}

Hp91 was taken up at $37^{\circ} \mathrm{C}$, but not at 16 and $4^{\circ} \mathrm{C}$ (Additional file 1: Figure S1), indicating that the uptake occurred via an energy dependent process, i.e. endocytosis. This was further supported by a significant inhibition of uptake of a fluorescently labeled version of Hp91 (Cp488) by sodium azide, which inhibits energy-dependent endocytosis (data not shown). The endocytic pathways include phagocytosis, macropinocytosis, clathrin-mediated endocytosis, and lipid-raft/caveolin-mediated endocytosis. The mechanism involved in the Hp91 uptake was determined using specific inhibitors of these endocytosis pathways. Latrunculin B (LatB), a specific phagocytosis inhibitor, did not reduce uptake of Hp91 (Figure 2A), whereas it completely abrogated uptake of the control Dextran FITC (data not shown). Phenylarsine oxide and chlorpromazine, inhibitors of clathrin-mediated endocytosis, significantly reduced the uptake of Hp91, suggesting that uptake occurs via clathrinmediated endocytosis (Figure 2B). In contrast, no effects were seen on the uptake of Hp91 for the lipid-raft/ caveolin-mediated endocytosis inhibitor, nystatin, or the 

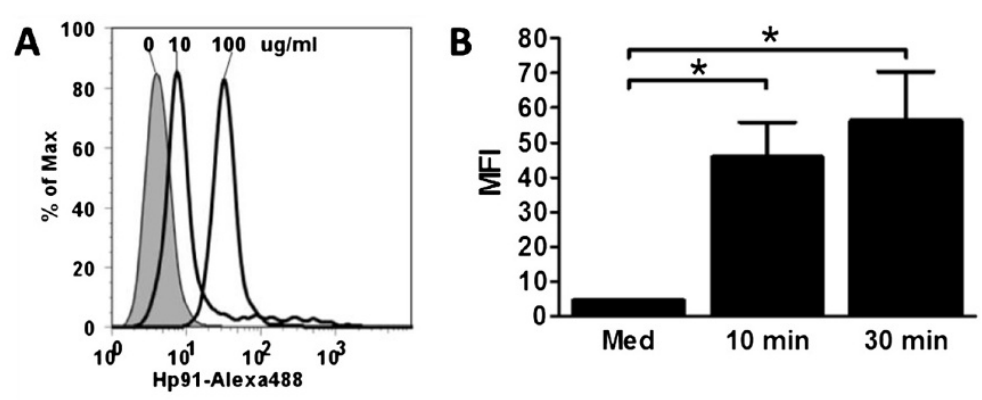

C
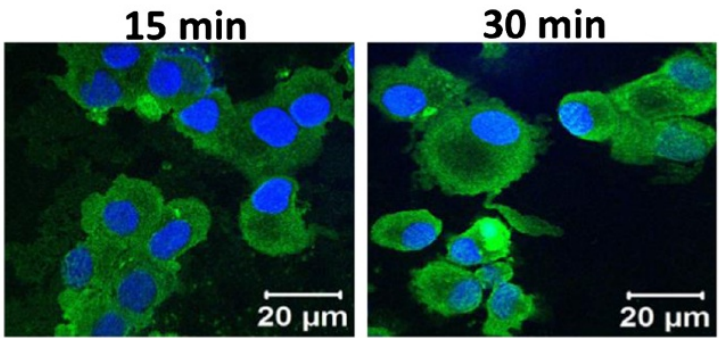

Hp91
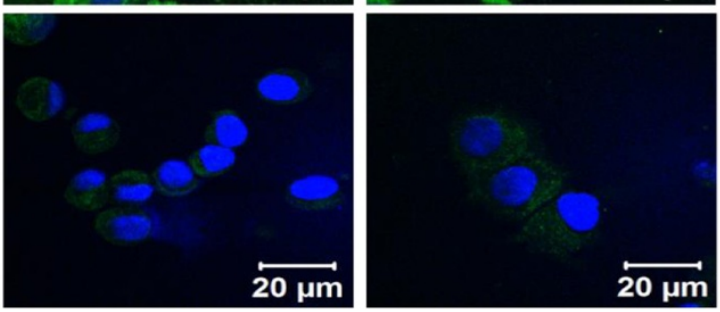

Hp121

D

E
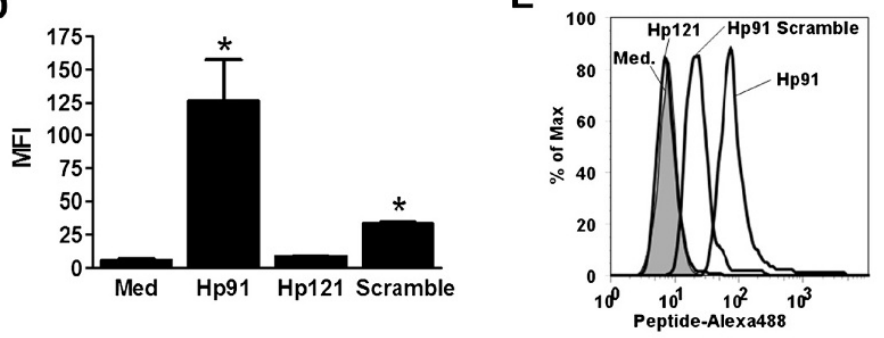

F

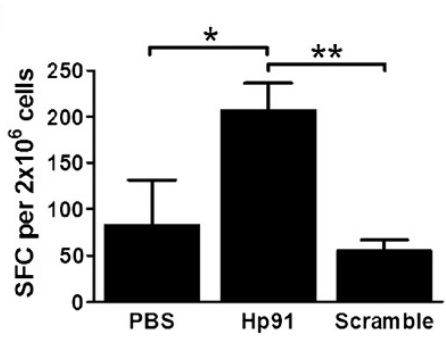

G

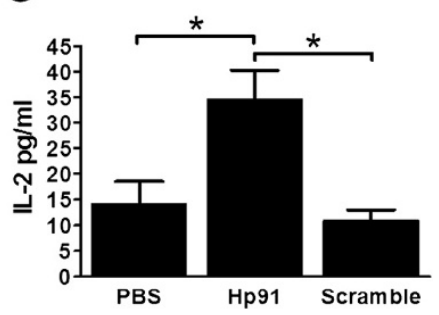

Figure 1 (See legend on next page.) 
(See figure on previous page.)

Figure 1 Hp91 uptake by DCs is dose, time, and sequence dependent. (A) Immature human DCs were pre-incubated on ice for 30 min, then incubated with biotinylated-Hp91 $(0,10$, or $100 \mu \mathrm{g} / \mathrm{ml})$ for $30 \mathrm{~min}$ at $37^{\circ} \mathrm{C}$. Cells were permeabilized with Cytofix/Cytoperm, stained with Streptavidin-Alexa 488, and analyzed by flow cytometry. The results shown is one representative experiment $(\mathrm{N}=6)$. (B) Immature human DCs were incubated with $100 \mathrm{mg} / \mathrm{ml}$ biotinylated $\mathrm{Hp} 91$ for 10 or 30 minutes, permeabilized, stained, and analyzed as above. Results shown are mean $( \pm$ SEM) of $\mathrm{N}=4$. (C) Pre-cooled immature human DCs (iDCs) were incubated on ice for $30 \mathrm{~min}$ with $200 \mu \mathrm{g} / \mathrm{ml}$ biotinylated Hp91 or Hp121 to allow peptide binding, washed, then incubated for 15, or 30 additional min at $37^{\circ} \mathrm{C}$. Cells were cytospun, fixed, permeabilized, and stained with Streptavidin-Alexa 488 to visualize biotinylated peptides (Green) and Hoechst DNA stain (Blue). Cells were imaged on a Zeiss LSM confocal microscope. Data shown is one representative experiment of $\mathrm{N}=3$. (D-E) Immature human DCs were pre-cooled on ice for $30 \mathrm{~min}$, then incubated with media only, biotinylated-Hp91, biotinylated-Hp121, or biotinylated-scrambled Hp91 ("Scramble") at $200 \mu \mathrm{g} / \mathrm{ml}$ for $30 \mathrm{~min}$ at $37^{\circ} \mathrm{C}$. Cells were permeabilized, stained, and analyzed by flow cytometry as above. (D) is mean ( \pm SEM) for $N=3$ and (E) is one representative experiment. ${ }^{*} \mathrm{p}<0.05$ compared to medium; Student's t-test. (F, G) Mice were immunized with OVA-I peptide in PBS with Hp91 or scrambled Hp91 peptide (250 $\mu$ g).

(F) Freshly isolated splenocytes from the immunized mice were examined in an OVA IFN- $\gamma$ ELISpot assay. (G) Supernatants were collected and analyzed for IL-2 secretion by ELISA. The data shown is mean $( \pm$ SEM) for $5-10$ mice/group. * $\mathrm{p}<0.05$ between groups; Student's t-test.

macropinocytosis inhibitor, amiloride (Figure 2B), indicating that the uptake was not occurring via neither lipid rafts nor macropinocytosis. These data show that the major mechanism for Hp91 uptake into DCs occurs via a clathrin coated pit dependent manner.

Hp91-mediated activation of DCs in vitro is dependent on TLR4, MyD88, and IFNaßR

Several receptors have been implicated in mediating the responses to HMGB1, including TLR4 [19-22,24,26]. Since our data show that receptor-mediated uptake, i.e. clathrin-mediated endocytosis, is clearly involved in the uptake of Hp91 (Figure 2B), we sought to identify the receptor(s) involved in Hp91-induced activation of DCs. Bone marrow (BM)-DCs generated from wild type and various knockout mice were exposed to Hp91. IL-6 secretion was significantly reduced in BM-DCs generated from MyD88-/-, TLR4-/-, and IFN $\alpha \beta R-/-$ knockout mice (Figure 3A), whereas IL-6 production from BM-DCs generated from TLR7-/- and IL-1R-/- knockout mice was comparable to wild type cells (Figure 3A), indicating that TLR4/MyD88 and IFN $\alpha \beta$ R are involved in the activation of DC by Hp91.

\section{Hp91-mediated activation of mouse antigen presenting} cells is clathrin- and dynamin-dependent

Since ligand engaged TLR4 is endocytosed in a dynamindependent manner for downstream signaling in macrophages exposed to LPS [35], we evaluated if Hp91 signals through a similar TLR4 mechanism as dynamin is part of
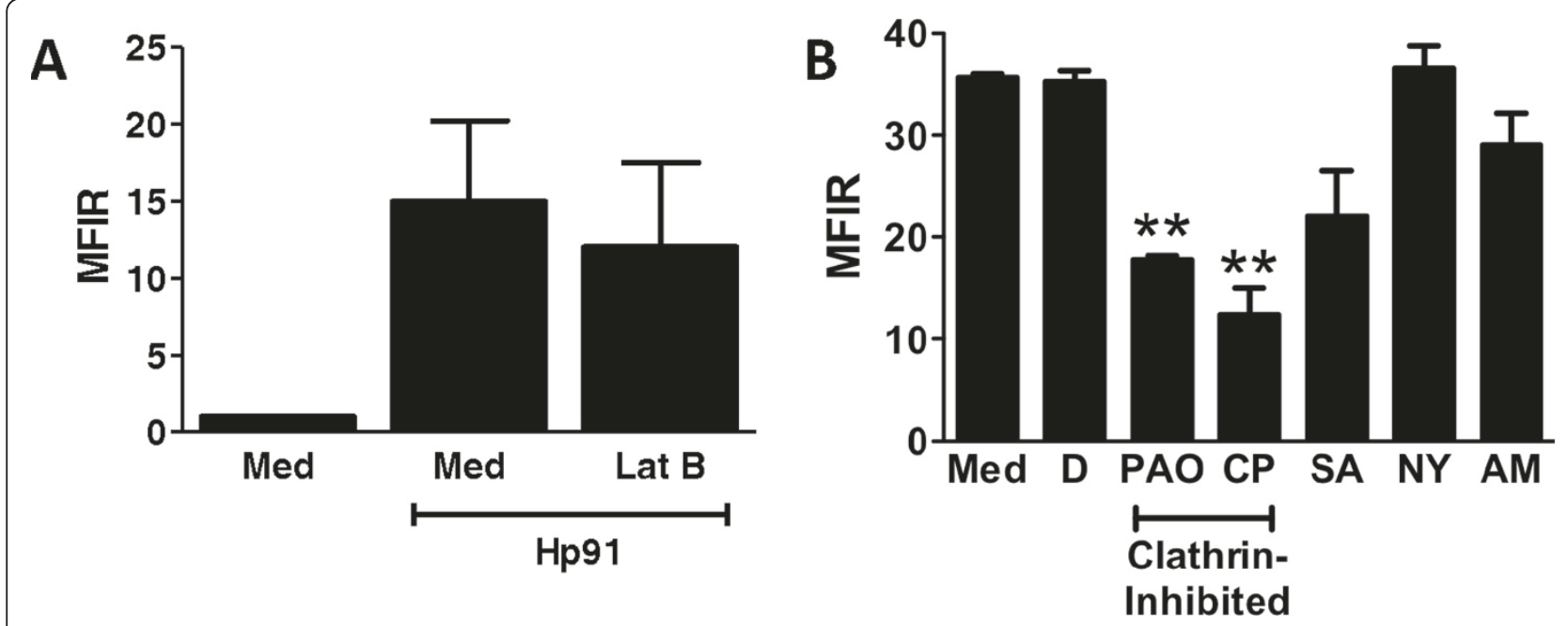

Figure 2 Uptake of Hp91 is via clathrin-mediated endocytosis. (A) Immature human DCs were pre-treated with the phagocytosis inhibitor Latrunculin B or medium only for 30 min before incubation with biotinylated-Hp91 for 30 min. Cells were permeabilized with Cytofix/Cytoperm, stained with Streptavidin-Alexa 488, and analyzed by flow cytometry. Data are mean ( \pm SEM) of $\mathrm{N}=5$. (B) Immature human DCs were pre-treated for 30 min with media only (Med), DMSO (D) = solvent control, the clathrin-mediated endocytosis inhibitors phenylarsine oxide (PAO) at $2 \mu M$ or chlorpromazine (CP) at $100 \mu \mathrm{M}$, the energy-dependent endocytosis inhibitor sodium azide (SA) at $10 \mathrm{mM}$, the caveolin-mediated endocytosis inhibitor nystatin (NY) at $20 \mu \mathrm{M}$, or the micropinocytosis inhibitor amiloride (AM) at $2 \mathrm{mM}$ before incubation with biotinylated Hp91 (200 $\mu \mathrm{g} / \mathrm{ml}$ ) for $30 \mathrm{~min}$. Cells were permeabilized, stained, and analyzed by flow cytometry as above. Results are mean $( \pm \mathrm{SEM})$ of $\mathrm{N}=3$. ${ }^{* *} \mathrm{p}<0.01 \mathrm{compared}$ to DMSO control; Student's t-test. 


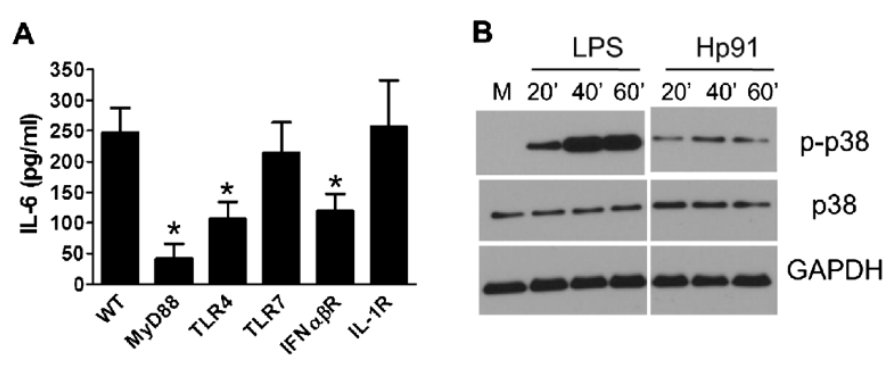

C

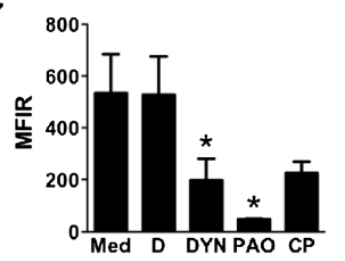

D

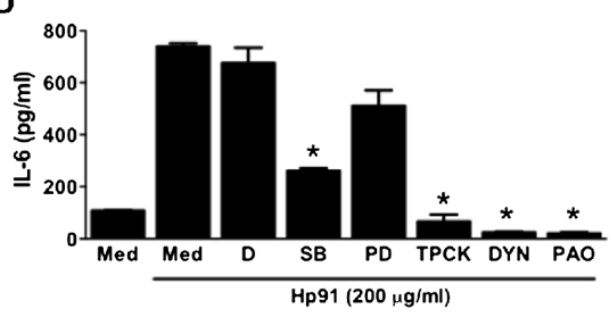

E

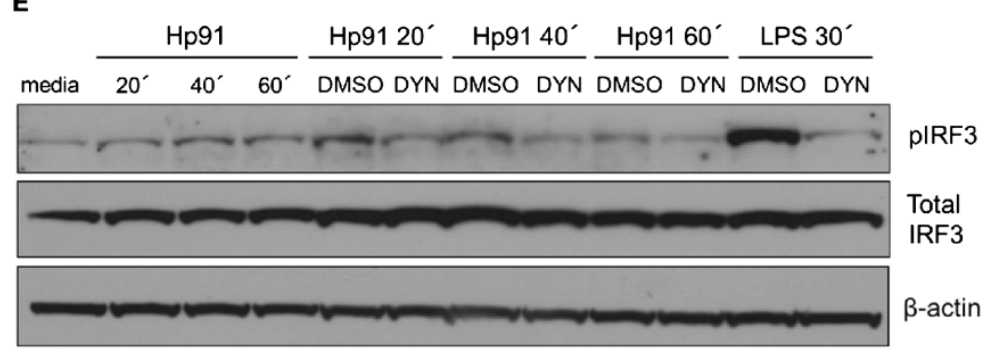

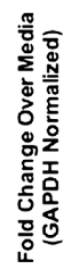

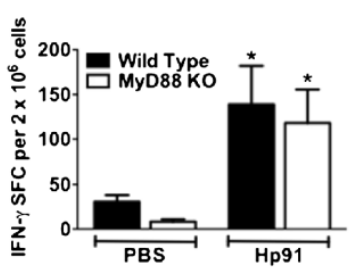

Figure 3 TLR4, MyD88, and MyD88-dependent and -independent pathways are necessary for Hp91-mediated activation of antigen presenting cells. (A) BM-DCs from wild type (WT) or knockout mice were exposed to $200 \mu \mathrm{g} / \mathrm{ml}$ Hp91. Supernatants were analyzed for IL-6 by ELISA. Results are mean ( \pm SEM) for $\mathrm{N}=3-5$. (B) $\mathbf{J} 774$ macrophages were stimulated for indicated times with $200 \mu \mathrm{g} / \mathrm{ml} \mathrm{Hp} 91,10 \mathrm{ng} / \mathrm{ml}$ LPS or left untreated (M). Lysates were analyzed for p-p38 by WB. Blots were probed with anti-p-p38, anti-p38, and anti-GAPDH antibodies. One of N=4. (C) $\mathrm{J} 774$ macrophages were pretreated with media (Med), DMSO control (D), Dynasore (DYN) $80 \mu \mathrm{M}$, phenylarsine oxide (PAO) $2 \mu \mathrm{M}$ or chlorpromazine (CP) $100 \mu \mathrm{M}$ before incubation with $200 \mu \mathrm{g} / \mathrm{ml}$ Cp488-labeled Hp91 for $30 \mathrm{~min}$. Cells were analyzed by flow cytometry. Results are mean ( \pm SEM), N=4. (D) J774

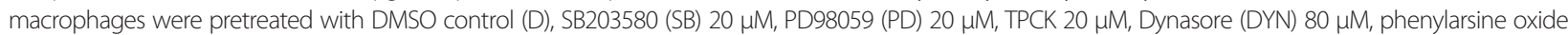
(PAO) $2 \mu \mathrm{M}$, or chlorpromazine (CP) $100 \mu \mathrm{M}$ then exposed to Hp91. Supernatants were analyzed for IL-6 by ELISA. Data are mean ( \pm SEM), N=3. (E) RAW 264.7 macrophages were pretreated with medium, DMSO control, or Dynasore (DYN) $80 \mu M$ prior to stimulation for indicated times with Hp91 $(200 \mu \mathrm{g} / \mathrm{ml})$, LPS $(10 \mathrm{ng} / \mathrm{ml})$ or media. Cell lysates were analyzed for $\mathrm{p}-$ IRF3. Immunoblots were probed with anti-p-IRF3, anti-IRF3, and anti- $\beta$ actin antibodies. (F) CDNA from stimulated $\mathbf{3} 774$ cells were evaluated for IFN-a2 mRNA by qPCR. Values are normalized against endogenous GAPDH controls, in duplicate. (G) Wildtype or MyD88-/- knockout mice were immunized with SIINFEKL peptide in PBS with or without Hp91. Splenocytes from immunized mice were cultured with SIINFEKL peptide $(2.5 \mathrm{\mu g} / \mathrm{ml})$. The number of IFN- $\gamma$-secreting cells was determined $18 \mathrm{~h}$ later. Data are mean ( \pm SEM), 5-10 mice/group. ${ }^{*} p<0.05$; Student's t-test.

the machinery for clathrin coated pit endocytosis [36]. The dynamin-dependent endocytosis inhibitor, dynasore, significantly inhibited uptake of $\mathrm{Hp} 91$ by macrophages (Figure $3 \mathrm{C}$ ), which is in agreement with the finding reported for LPS [35]. The clathrin-mediated endocytosis inhibitor phenylarsine oxide also inhibited uptake of Hp91 by macrophages (Figure $3 \mathrm{C}$ ). In addition, blocking uptake of Hp91 via dynamin or clathrin mediated endocytosis significantly reduced IL-6 secretion (Figure 3D). Since a reduction in Hp91-mediated IL-6 secretion was observed in 
human DCs following pretreatment with the p38MAPK and NF-kB inhibitors (Figure 4), we evaluated if the same was true for mouse macrophages. As was seen in human DCs, inhibition of p38MAPK or NF-kB signaling cascades significantly lowered the amount of Hp91-stimulated IL-6 secreted from mouse macrophages (Figure 3D), further confirming the involvement of p38MAPK and NF- $\mathrm{kB}$ in Hp91 signaling.

\section{DC activation by $\mathrm{Hp} 91$ peptide involves signaling via a p38 MAPK and NF-KB dependent pathway}

Our previous findings have shown involvement of the p38MAPK pathway in the HMGB1 B box-induced secretion of IL-6 by human DCs [37]. Pretreatment of human DCs with the p38MAPK inhibitor SB203580, and the NF$\mathrm{\kappa B}$ inhibitor N-p-Tosyl-L-phenylalanine chloromethyl ketone (TPCK), significantly reduced the Hp91-induced IL-6 production in DCs (Figure 4). In contrast, PD98059, a MEK1 inhibitor, failed to significantly decrease the IL-6 production (Figure 4). The p38MAPK pathway was further confirmed by immunoblotting for phosphorylated p38MAPK (p-p38). p-p38 was up-regulated in mouse BM-DCs after 40-60 min of Hp91 stimulation (Figure 3B). In most experiments, up-regulation of p-p38 was observed as early as 20 minutes after Hp91 stimulation. These results suggest that $\mathrm{Hp} 91$ induced the DC activation in a p38MAPK and NF-kB pathway dependent manner.

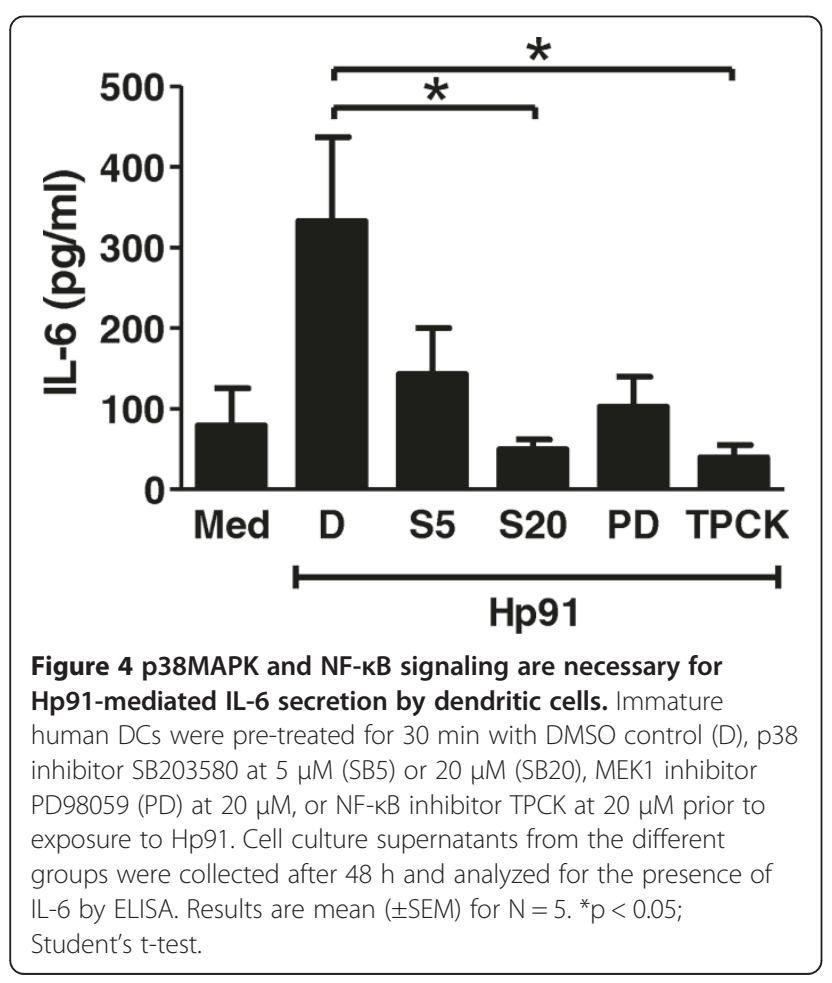

Hp91 activates IRF3 and subsequent IFNa production in antigen presenting cells

TLR4 can signal through MyD88 dependent and independent pathways, whereas other TLRs are MyD88dependent. Our data indicate that both pathways might be involved in Hp91 signaling since a decrease in Hp91induced IL-6 secretion was observed for both MyD88-/and IFN $\alpha \beta \mathrm{R}-/-$ knockout BM-DCs (Figure 3A). We investigated if $\mathrm{Hp} 91$ activated the MyD88 independen signaling pathway by investigating phosphorylation of the downstream interferon regulatory factor 3 (IRF3) transcription factor. The phosphorylation of IRF3 (pIRF3) was up-regulated after $\mathrm{Hp} 91$ stimulation as early as $20 \mathrm{~min}$ (Figure 3E) and at a maximum around $40 \mathrm{~min}$ after stimulation. In addition blocking $\mathrm{Hp} 91$ endocytosis with dynasore reduced the phosphorylation of IRF3 at 20,40, and $60 \mathrm{~min}$ (Figure 3E). To further investigate involvement of the MyD88-independent signaling pathway, we evaluated IFN- $\alpha$ mRNA expression in Hp91-stimulated mouse macrophages as this factor should be up-regulated by pIRF3. Although lower than the increase induced by LPS, Hp91 induced a 99-fold increase in IFN- $\alpha$ mRNA levels (Figure 3F). These findings suggest that Hp91 uptake is required for MyD88-independent activation of the IRF3 pathway and production of IFN- $\alpha$.

\section{MyD88 signaling is not required for Hp91-elicited CTL responses in vivo}

Since Hp91 activated both the MyD88 dependent as well as independent pathways (Figure 3A and $3 \mathrm{E}$ ), we tested if MyD88 was required for Hp91-induced CD8+ CTL responses in vivo. We immunized age-matched wild type and MyD88-/- knockout mice with OVA-I (SIINFEKL) peptide co-injected with PBS or Hp91. Both wild type and MyD88-/- knockout mice showed similar antigen-specific cellular immune responses, as demonstrated by increased number of OVA-specific IFN- $\gamma$ secreting cells (Figure 3G) suggesting that induction of this antigen specific CD8+ CTL response did not require MyD88 signaling. The lack of IL-6 secretion in MyD88-/- DCs after Hp91 exposure indicated that Hp91 can signal through MyD88, whereas the adjuvant effect elicited by $\mathrm{Hp} 91$ in vivo is MyD88 independent.

\section{Discussion}

Endogenous TLR agonists and inflammatory mediators are attractive candidates as vaccine adjuvants, especially for subunit vaccines that many times are poorly immunogenic, and the mechanism through which these types of adjutants augment immune responses is via the innate immunity. There is a great need for safe and potent adjuvants seeing that and we have previously shown that the 18 amino acid long immunostimulatory peptide Hp91, derived from the B box of the HMGB1 protein, is a potent 
stimulus for human DCs with the ability to generate a Th1-type immune response in vitro [32]. In addition, Hp91 acted as adjuvant in vivo, inducing cellular immune responses to peptide and both cellular and humoral immune responses to protein antigen [33]. In this study we characterize the mechanism of action for this adjuvant and show here that Hp91 exerted its immunostimulatory effects on DCs by inducing cellular uptake and activating signaling cascades. The Hp91 peptide was taken up into cells very rapidly via clathrin-mediated endocytosis in a sequence specific manner. Scrambling the amino acid sequence of $\mathrm{Hp} 91$ resulted in a great reduction of binding/uptake by cells, indicating that it is neither the total charge nor total hydrophobicity that is important for uptake rather the unique amino acid sequence. Further characterization showed that $\mathrm{Hp} 91$ mediated activation of DCs, i.e. IL-6 production in vitro, was dependent on TLR4, MyD88, and IFN $\alpha \beta R$, whereas MyD88 signaling in vivo was not required for activation of CD8+ CTL responses.

Multiple HMGB1 binding and signaling events mediate activation of innate immune responses. The binding and uptake of Hp91 by DCs was a rapid and sequence dependent event and we found that the internalization occurred via clathrin dependent endocytosis. Since clathrin-mediated endocytosis is a receptor dependent uptake, we explored possible receptors involved in the uptake of Hp91. Several receptors have been implicated, including RAGE, TLR4, TLR2, CD24/Siglec-10. HMGB1 has been shown to contribute to LPS-mediated DC maturation via RAGE [18]. TLR2 and TLR4 have been shown to be involved in HMGB1 signaling in vitro [19-23]. In vivo data have shown binding and signaling through TLR4 to be involved in HMGB1-induced cytokine release, i.e. inflammation leading to tissue damage in the body $[20,38]$.

The C-terminal motif of HMGB1 (150-183 amino acids) is responsible for RAGE binding [38], whereas the C-terminal end contains the TLR4 binding site. The Hp91 peptide is located in the B box area of HMGB1 protein and contains the TLR4 binding domain and we found that the ability to bind TLR4 was still intact in the Hp91 peptide.

It has been shown that LPS, a TLR4 ligand, binds TLR4, and is subsequently endocytosed together with the receptor [35] and this seems also to be the case for Hp91 peptide. By evaluating IL-6 secretion from knockout mice, we show that Hp91-stimulated activation of DCs is dependent on TLR4 and its downstream adaptor protein, MyD88 and further downstream signaling via p38MAPK and NF-кB. We have previously shown the involvement of the p38MAPK pathway in induction of IL-6 secretion in human DCs by the HMGB1 subunit B box [37] and others have shown that this pathway is involved in HMGB-1 induced activation of neutrophils [39]. This indicates that both the HMGB1 derived peptide and the whole protein have the ability to activate the p38MAPK pathway and that the activating sequence seems to be located within the Hp91 peptide.

Hp91 acts as adjuvant in vivo; inducing cellular immune responses to peptide and both cellular and humoral immune responses to protein antigen [33]. Immunization of MyD88-/- mice, using Hp91 as adjuvant, induced cellular immune responses comparable to WT mice. This suggests that even though MyD88 was required in vitro for Hp91-mediated IL-6 secretion in DCs, the Hp91induced cellular immune responses in vivo are MyD88independent. Furthermore, active uptake of Hp91 was required for signaling through this MyD88-independent pathway. Hp91 induces the in vivo production of Th1type cytokines, such as IL-12, and IFN- $\gamma$ [33]. The Th1 cellular immune response is highly characterized by IFN responses and we found that Hp91-induced a signaling cascade activating the type I IFN pathway via IRF3, leading to elevated expression of IFN- $\alpha$ mRNA. Blocking the type I IFN receptor dampened the immune response to another potential adjuvant, i.e. Poly I:C, indicating that type I IFN play an important role in the immune activation induced by this adjuvant [40] Our data suggest that the activation of DCs by Hp91 is dependent on an autocrine type I IFN feedback loop as cells derived from IFN $\alpha \beta R$ knockout mouse failed to respond. This combined with the result showing that MyD88 was not necessary in vivo for cellular immune responses, suggests that the MyD88-independent pathway plays a prominent role in $\mathrm{Hp} 91$ induction of cellular immune responses in vivo.

These new findings provide a better understanding of the cellular mechanisms by which the immunogenic peptide induces potent immune responses. This peptide activates myeloid DCs and should be suitable as an adjuvant in cancer immunotherapies as well as vaccines against infectious diseases.

\section{Additional file}

Additional file 1: Uptake of Hp91 is temperature dependent. (A-B) Immature human DCs were pre-cooled on ice for $30 \mathrm{~min}$, then incubated with biotinylated $\mathrm{Hp} 91(200 \mu \mathrm{g} / \mathrm{ml})$ for $30 \mathrm{~min}$ at 4,16 , or $37^{\circ} \mathrm{C}$. Cells were permeabilized with Cytofix/Cytoperm, stained with Streptavidin-Alexa488, and analyzed by flow cytometry. (A) Data are mean ( \pm SEM) of $\mathrm{N}=3$ and (B) is a representative result. ${ }^{* *} \mathrm{p}<0.001$; Student's t-test. Data are mean $( \pm$ SEM) of triplicate samples, but data is representative of 3 independent experiments.

Competing interests

The authors declare that they have no conflict of interest.

Authors' contributions

RS, JFF, ML, TH, BM, DC, SE, BTM and DM participated in the study design. RS, DF, LL, FE, JFF, SS and SS carried out the experimental studies. RS, JFF, 
BTM and DM wrote the paper and participated in manuscript revision. All authors read and approved the final manuscript.

\section{Acknowledgements}

This work was supported by 5 U54 CA119335 from the National Institutes of Health/NCI (to S.E. and D.M.), the U.S. Army Medical Research and Materiel Command under agreement number W81XWH-07-1-0412 (to D.M.) and the Swedish Research Council Al52731 (to ML), the Swedish Physicians against AIDS Research Foundation, the Swedish International Development Cooperation Agency; SIDA SARC, VINNMER for Vinnova, Linköping University Hospital Research Fund, CALF and the Swedish Society of Medicine (to M.L.).

\section{Author details}

${ }^{1}$ Rebecca and John Moores Cancer Center, University of California San Diego (UCSD), 3855 Health Sciences Dr., La Jolla, CA 92093-0815, USA.

${ }^{2}$ Pharmaceutical and Biological Laboratory Technology, University College Ghent, Ghent, Belgium. ${ }^{3}$ Molecular Virology, Department of Clinical and Experimental Medicine, Linköping University, Linköping, Sweden. ${ }^{4}$ Genelux Corporation, San Diego, CA, USA. ${ }^{5}$ Department of NanoEngineering, UCSD, La Jolla, CA, USA.

Received: 29 May 2014 Accepted: 10 July 2014

Published: 14 August 2014

\section{References}

1. Takeda K, Kaisho T, Akira S: Toll-like receptors. Annu Rev Immunol 2003, 21:335-376.

2. Banchereau J, Steinman RM: Dendritic cells and the control of immunity. Nature 1998, 392:245-252.

3. Bianchi ME: DAMPs, PAMPs and alarmins: all we need to know about danger. J Leukoc Biol 2007, 81:1-5.

4. Matzinger P: Tolerance, danger, and the extended family. Annu Rev Immunol 1994, 12:991-1045.

5. Gallucci S, Matzinger P: Danger signals: SOS to the immune system. Curr Opin Immunol 2001, 13:114-119.

6. Gallucci S, Lolkema M, Matzinger P: Natural adjuvants: endogenous activators of dendritic cells. Nat Med 1999, 5:1249-1255.

7. Sauter B, Albert ML, Francisco L, Larsson M, Somersan S, Bhardwaj N: Consequences of cell death: exposure to necrotic tumor cells, but not primary tissue cells or apoptotic cells, induces the maturation of immunostimulatory dendritic cells. J Exp Med 2000, 191:423-434.

8. Basu S, Binder RJ, Suto R, Anderson KM, Srivastava PK: Necrotic but not apoptotic cell death releases heat shock proteins, which deliver a partial maturation signal to dendritic cells and activate the NF-kappa B pathway. Int Immuno/ 2000, 12:1539-1546.

9. Agresti A, Bianchi ME: HMGB proteins and gene expression. Curr Opin Genet Dev 2003, 13:170-178.

10. Bustin M, Lehn DA, Landsman D: Structural features of the HMG chromosomal proteins and their genes. Biochimica Et Biophysica Acta 1990, 1049:231-243.

11. Bustin M, Reeves R: High-mobility-group chromosomal proteins: architectural components that facilitate chromatin function. Prog Nucleic Acid Res Mol Biol 1996, 54:35-100

12. Wang $H$, Vishnubhakat JM, Bloom $O$, Zhang M, Ombrellino M, Sama A, Tracey $\mathrm{KJ}$ : Proinflammatory cytokines (tumor necrosis factor and interleukin 1) stimulate release of high mobility group protein-1 by pituicytes. Surgery 1999, 126:389-392.

13. Andersson $U$, Wang $H$, Palmblad $K$, Aveberger $A C$, Bloom $O$, Erlandsson_Harris H, Janson A, Kokkola R, Zhang M, Yang H, Tracey KJ: High mobility group 1 protein (HMG-1) stimulates proinflammatory cytokine synthesis in human monocytes. The Journal of Experimental Medicine 2000, 192:565-570.

14. Hreggvidsdottir HS, Ostberg T, Wahamaa H, Schierbeck H, Aveberger AC, Klevenvall L, Palmblad K, Ottosson L, Andersson U, Harris HE: The alarmin HMGB1 acts in synergy with endogenous and exogenous danger signals to promote inflammation. J Leukoc Biol 2009, 86:655-662.

15. Scaffidi P, Misteli T, Bianchi ME: Release of chromatin protein HMGB1 by necrotic cells triggers inflammation. Nature 2002, 418:191-195.

16. Rovere-Querini P, Capobianco A, Scaffidi P, Valentinis B, Catalanotti F, Giazzon M, Dumitriu IE, Muller S, lannacone M, Traversari C, Bianchi ME, Manfredi A: HMGB1 is an endogenous immune adjuvant released by necrotic cells. EMBO Rep 2004, 5:825-830.

17. Hori O, Brett J, Slattery T, Cao R, Zhang J, Chen JX, Nagashima M, Lundh ER, Vijay S, Nitecki D, Morser J, Stern D, Schmidt AM: The receptor for advanced glycation end products (RAGE) is a cellular binding site for amphoterin. Mediation of neurite outgrowth and co-expression of rage and amphoterin in the developing nervous system. J Biol Chem 1995, 270:25752-25761.

18. Dumitriu IE, Baruah P, Bianchi ME, Manfredi AA, Rovere-Querini P: Requirement of HMGB1 and RAGE for the maturation of human plasmacytoid dendritic cells. Eur J Immunol 2005, 35:2184-2190.

19. Park JS, Svetkauskaite D, He Q, Kim JY, Strassheim D, Ishizaka A, Abraham E: Involvement of toll-like receptors 2 and 4 in cellular activation by high mobility group box 1 protein. J Biol Chem 2004, 279:7370-7377.

20. van Zoelen MA, Yang H, Florquin S, Meijers JC, Akira S, Arnold B, Nawroth PP, Bierhaus A, Tracey KJ, van der Poll T: Role of Toll-Like Receptors 2 and 4, and the Receptor for Advanced Glycation End Products (Rage) in Hmgb1 Induced Inflammation in Vivo. Shock 2009, 31(3):280-284.

21. Yu M, Wang H, Ding A, Golenbock DT, Latz E, Czura CJ, Fenton MJ, Tracey $\mathrm{KJ}$, Yang H: HMGB1 signals through toll-like receptor (TLR) 4 and TLR2. Shock 2006, 26:174-179.

22. Park JS, Gamboni-Robertson F, He Q, Svetkauskaite D, Kim JY, Strassheim D, Sohn JW, Yamada S, Maruyama I, Banerjee A, Ishizaka A, Abraham E: High mobility group box 1 protein interacts with multiple Toll-like receptors. Am J Physiol Cell Physiol 2006, 290:C917-C924.

23. Yang H, Hreggvidsdottir HS, Palmblad K, Wang H, Ochani M, Li J, Lu B, Chavan S, Rosas-Ballina M, Al-Abed Y, Akira S, Bierhaus A, Erlandsson-Harris $\mathrm{H}$, Andersson $\mathrm{U}$, Tracey $\mathrm{KJ}$ : A critical cysteine is required for HMGB1 binding to Toll-like receptor 4 and activation of macrophage cytokine release. Proc Natl Acad Sci U S A 2010, 107:11942-11947.

24. Ivanov S, Dragoi AM, Wang X, Dallacosta C, Louten J, Musco G, Sitia G, Yap GS, Wan Y, Biron CA, Bianchi ME, Wang H, Chu WM: A novel role for HMGB1 in TLR9-mediated inflammatory responses to CpG-DNA. Blood 2007, 110:1970-1981

25. Orlova W, Choi EY, Xie C, Chavakis E, Bierhaus A, Ihanus E, Ballantyne CM, Gahmberg CG, Bianchi ME, Nawroth PP, Chavakis T: A novel pathway of HMGB1-mediated inflammatory cell recruitment that requires Mac-1integrin. EMBO J 2007, 26:1129-1139.

26. Rauvala $H$, Rouhiainen $A$ : Physiological and pathophysiological outcomes of the interactions of HMGB1 with cell surface receptors. Biochim Biophys Acta 2010, 1799:164-170.

27. Salmivirta M, Rauvala H, Elenius K, Jalkanen M: Neurite growth-promoting protein (amphoterin, p30) binds syndecan. Exp Cell Res 1992, 200:444-451.

28. Milev P, Chiba A, Haring M, Rauvala H, Schachner M, Ranscht B, Margolis RK, Margolis RU: High affinity binding and overlapping localization of neurocan and phosphacan/protein-tyrosine phosphatase-zeta/beta with tenascin-R, amphoterin, and the heparin-binding growth-associated molecule. J Biol Chem 1998, 273:6998-7005.

29. Chen GY, Tang J, Zheng P, Liu Y: CD24 and Siglec-10 selectively repress tissue damage-induced immune responses. Science 2009, 323:1722-1725.

30. Li J, Kokkola R, Tabibzadeh S, Yang R, Ochani M, Qiang X, Harris HE, Czura CJ, Wang H, Ulloa L, Wang H, Warren HS, Moldawer LL, Fink MP, Andersson $\mathrm{U}$, Tracey KJ, Yang H: Structural basis for the proinflammatory cytokine activity of high mobility group box 1. Mol Med 2003, 9:37-45.

31. Yang $H$, Wang $H$, Czura CJ, Tracey KJ: HMGB1 as a cytokine and therapeutic target. J Endotoxin Res 2002, 8:469-472.

32. Telusma G, Datta S, Mihajlov I, Ma W, Li J, Yang H, Newman W, Messmer BT, Minev B, Schmidt-Wolf IG, Tracey KJ, Chiorazzi N, Messmer D: Dendritic cell activating peptides induce distinct cytokine profiles. Int Immunol 2006, 18:1563-1573

33. Saenz R, Souza Cda S, Huang CT, Larsson M, Esener S, Messmer D: HMGB1derived peptide acts as adjuvant inducing immune responses to peptide and protein antigen. Vaccine 2010, 28:7556-7562.

34. Inaba K, Inaba M, Romani N, Aya H, Deguchi M, Ikehara S, Muramatsu S, Steinman RM: Generation of large numbers of dendritic cells from mouse bone marrow cultures supplemented with granulocyte/macrophage colony-stimulating factor. J Exp Med 1992, 176:1693-1702.

35. Kagan JC, Su T, Horng T, Chow A, Akira S, Medzhitov R: TRAM couples endocytosis of Toll-like receptor 4 to the induction of interferon-beta. Nat Immunol 2008, 9:361-368.

36. Macia E, Ehrlich M, Massol R, Boucrot E, Brunner C, Kirchhausen T: Dynasore, a cell-permeable inhibitor of dynamin. Dev Cell 2006, 10:839-850. 
37. Messmer D, Yang H, Telusma G, Knoll F, Li J, Messmer B, Tracey KJ, Chiorazzi $\mathrm{N}$ : High mobility group box protein 1: an endogenous signal for dendritic cell maturation and Th1 polarization. J Immunol 2004, 173:307-313.

38. Huttunen HJ, Kuja-Panula J, Rauvala H: Receptor for advanced glycation end products (RAGE) signaling induces CREB-dependent chromogranin expression during neuronal differentiation. J Biol Chem 2002, 277:38635-38646.

39. Park JS, Arcaroli J, Yum HK, Yang H, Wang H, Yang KY, Choe KH, Strassheim D, Pitts TM, Tracey K, Abraham E: Activation of gene expression in human neutrophils by high mobility group box 1 protein. Am J Physiol Cell Physiol 2003, 284:C870-C879.

40. Caskey M, Lefebvre F, Filali-Mouhim A, Cameron MJ, Goulet JP, Haddad EK, Breton G, Trumpfheller C, Pollak S, Shimeliovich I, Duque-Alarcon A, Pan L, Nelkenbaum A, Salazar AM, Schlesinger SJ, Steinman RM, Sekaly RP: Synthetic doublestranded RNA induces innate immune responses similar to a live viral vaccine in humans. J Exp Med 2011, 208:2357-2366.

doi:10.1186/1479-5876-12-211

Cite this article as: Saenz et al:: TLR4-dependent activation of dendritic cells by an HMGB1-derived peptide adjuvant. Journal of Translational Medicine 2014 12:211.

\section{Submit your next manuscript to BioMed Central and take full advantage of:}

- Convenient online submission

- Thorough peer review

- No space constraints or color figure charges

- Immediate publication on acceptance

- Inclusion in PubMed, CAS, Scopus and Google Scholar

- Research which is freely available for redistribution 